\title{
LOW COST PROTOCOL VERSUS SHORT PROTOCOL FOR CONTROLLED OVARIAN STIMULATION IN ICSI TRIALS
}

\author{
Salem H. H. ${ }^{1}$; Nassar A. M. ${ }^{1 \& 2}$; Askalany N. A. ${ }^{3}$, Kassem K. ${ }^{2 \& 4}$ \\ ${ }^{1}$ Department of Obstetrics and Gynecology Al Azhar University. ${ }^{2}$ Al Azhar ART Unit, IICPSR, \\ Al Azhar University. ${ }^{3}$ Department of Obstetrics and Gynecology Cairo University. \\ ${ }^{4}$ Department of Community Medicine Al Azhar University.
}

\section{ABSTRACT}

Design: A prospective randomized controlled study carried out at Al Azhar ART unit in the International Islamic center for population studies and research (IICPSR) Al Azhar university, from July 2005 to March 2007.

Objective : To compare the effectiveness of low cost Protocol versus the short (flare up) protocol.

Methods: Two hundreds and thirty five couples have been recruited in this study, all of them were planned for an ICSI either due to male subfertility of unexplained infertility.

Results: The shori protocol was found to have significantly higher number of oocyies as well as the available embryos for transfer than in low cost protocol. The Low cost protocol was found to be of very low cost than the short protocol (in regard to the total number of hMG ampoules used per cycle) $(\mathrm{P}<0.001)$. Pregnancy rate was found to be slightly higher in the short protocol $(17 \%)$ than the low cost protocol $(15 \%)$, yet this was statistically insignificant $(\mathrm{P}=0.7)$.

Conclusion: The low cost protocol is less expensive than the short protocol so, it can be used as an alternative to the short protocol especially in couples undergoing an ICSI and/or TESE, aiming to reduce the cost.

\section{INTRODUCTION}

Although the first successful pregnancy following IVF occurred during a natural cycle, the increasing efficacy of assisted reproductive procedures has been obtained by steady more expensive hormone stimulation protocols and improved techniques for gamete and embryo handling (1).

Conventional ovarian stimulation protocols aim to stimulate the growth of many follicles to obtain multiple oocyles for in vitro fertilization (IVF) and thus multiple embryos, allowing embryo selection for transfer $^{(2)}$. The currently applied standard IVF protocols take a long time, and are complex, expensive, and also are not without risk. Problems related to ovarian stimulation include cmotional stress, abdominal discomfort, short-term complications such as ovarian Hyper-Stimulation Syndrome and multiple gestation, as well as uncertainites regarding long-term health

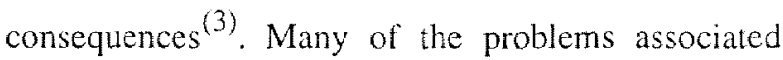
with current IVF stimulation regimens are related to the non physiological approach to ovarian hyper stimulation $^{(4)}$

To date, IVF practice has focussed on optimizing success in terms of pregnancy rate per started IVF cycle. Profound ovarian stimulation is therefore applied, despite the above mentioned side effects, risks, and high costs. If the balance between the risks and benefits of IVF treatment is to improve ART outcome, a paradigm shift is required in the approach to treatment and in the way success from IVF is defined $^{(5)}$. 
The modern trend in ART is to reduce the number of embryos transferred to a single embryo (SET) or double embryos (DET) to overcome multiple gestations and its unfavorable obstetric outcome. So, it is now more logic to restrict ovarian stimulation to get 5-10 growing follicles, (Oocytes retrieved) and 3-5 embryos to select 1-2 good quality embryo(s) for transfer.

In 1993, Corfman described a novel ovarian stimulation protocol termed minimal stimulation (MSP), when used in In-Vitro Fertilization program (IVF); this protocol gave a clinical pregnancy rate comparable to pure hMG stimulation at lower expense. Although MSP has been reported to be effective for ovulation induction, a widespread search of the literature shows only a few studies using it ${ }^{(6)}$.

Many factors influence the success of IVF-ET including the age of the female partner ${ }^{(7)}$, early follicular phase FSH concentration ${ }^{(8)}$, evidence of good ovarian reserve ${ }^{(9)}$, and the number of oocytes retrieved. However, the most important determinant of IVF-ET success is the ovarian stimulation protocol employed.

\section{MATERIALS \& METHODS}

Beginning in July 2005 until March 2007, the low cost protocol was offered as a less expensive stimulation choice for patients below 40 years of age undergoing ICSI cycles $(n=139)$. The advantages and disadvantages of such protocol were carefully discussed with the couples and clearly understood by patients selected for such protocol. Financial consideration was the primary reason for accepting that protocol.

Ninety six women fulfilling the same physical criteria undergoing an ICSI cycle using the standard (flare up) short protocol of GnRH-a and hMG were used as a control group.

The two groups were matched as regard their age, basal (day 3) serum levels of FSH, LH, $\mathrm{E}_{2}$ and $\mathrm{BMI}$ as well as the base line U/S on day 3 of the cycle ${ }^{(10)}$.

This study is designed to compare the effectiveness of low cost Protocol versus the short (flare up) protocol.

In low cost protocol group $(n=139)$, Clomiphene citrate ( $50 \mathrm{mg}$ twice daily) started from $3^{\text {rd }}$ to $7^{\text {th }}$ day of the cycle and human menopausal gonadotropin (hMG) (150 I.U/day) in a single dose from day 6 , then ultrasonic folliculometry from day 9 of the stimulated cycle until one or more follicle(s) reached $16 \mathrm{~mm}$ in diameter, GnRH-a $(0.25 \mathrm{mg})$ S.C daily injection until 24 hours after hCG triggering dose (10,000 1.U). Thirty six hours later, ovum pick up is done and followed by ET on $3^{\text {rd }}$ day.

In short protocol group $(\mathrm{n}=96), \quad \mathrm{GnRH}-\mathrm{a}$ (decapeptil 0,1 S.C daily injection started from day one of the stimulated cycle, hMG $225 \mathrm{mIU}$ single daily injection started from $2^{\text {nd }}$ day and ultrasonic folliculometry from day 7 until the day of $\mathrm{HCG}$ (10,000 IU). Ovum pick up and E.T were done similar as in the low cost group.

In both groups, luteal phase support was done using micronized progesterone (Uterogestan ${ }^{(0)} 100$ mg) was given as 2 tablets twice daily as well as vaginal progesterone ovules (Cyclogest, $200 \mathrm{mg}$ ) twice daily.

Clinical pregnancy was defined as a presence of a gestational sac by ultrasound 2 weeks after a positive quantitative $\beta$-hCG test. Statistical analysis was performed by using the student's $t$ test or $\chi^{2}$ test where appropriate.

\section{RESULTS}

This study involved 235 couples complaining of male subfertility. Ninety six couples $(41 \%)$ have been managed by short protocol while one hundred and thirty nine $(59 \%)$ were treated by low cost protocol (Table I). 
Both groups showed no statistical significant differences as regards their age of female partners. body mass index (BMI) as well as basal serum levels of FSH, LH and $E_{2}$ (Table II).

The number of growing follicles was found of high statistical significance in short protocol group than in the low cost one $(P<0.001)$. The number of oocytes retrieved and the available grade (A) embryos were found less in the low cost group than in the short protocol group with a significant difference $(\mathrm{P}<0.01)$ (Table III).

The total number of hMG ampoules used per treatment cycle in short protocol group was found highly significant than that used in low cost group ( $P$ $<0.003$ ) (Table IV).

In short protocol group, $19 \%$ of patients failed to complete the procedure because of poor ovarian response $(2.1 \%)$, negative TESE $(6.3 \%)$, and negative fertilization due to severe poor sperm quality
(11.5\%), While thitly two percent of cases failed to complete the procedure in the low cost group due to negative TESE (20.1\%), poor ovarian response $(2.88 \%)$, or negative fertilizations due to very poor sperm qualitiy $(8.6 \%)$. In comparing these uncompleted cycle rates, there were no statistically significant differences (Table V).

Comparing the pregnancy rates per completed cycles, the percentage of the pregnancy rate per embryo transfer was found to be (17\%) in the short protocol group and $(15 \%)$ in the low cost group, with no statistically significant differences (Table VI).

Regarding the occurrence of multiple gestation, there was only three cases of twins reported in the short protocol group (3.9\%) and 5 cases (5.2\%) in the low cost group with no reported triplets or more in both groups (Table VII).

Fortunately, in both studied groups, there were no cases of ovarian hyperstimulation syndrome (OHSS).

Table I : Distribution of the cases in the studied groups .

\begin{tabular}{|l|c|c|}
\hline \multicolumn{1}{|c|}{ Protocol } & No. of cases & $\%$ \\
\hline Short & 96 & 41.0 \\
\hline Low cost & 139 & 59.0 \\
\hline Total & 235 & 100 \\
\hline
\end{tabular}

Table II : Mean and SD of Age, BMI and basal hormones in both groups.

\begin{tabular}{|l|c|c|c|c|c|}
\hline \multirow{2}{*}{ Protocol } & Age & BMI & FSH & LH & E2 \\
\cline { 2 - 6 } & Mean \pm SD & Mean \pm SD & Mean \pm SD & Mean \pm SD & Mean \pm SD \\
\hline Short $(n=96)$ & $29.49 \pm 5.04$ & $25.15 \pm 2.02$ & $6.92 \pm 2.5$ & $5.52 \pm 1.26$ & $49.32 \pm 19.33$ \\
\hline Low cost $(\mathrm{n}=139)$ & $29.13 \pm 4.95$ & $24.87 \pm 2.06$ & $6.63 \pm 2.68$ & $5.49 \pm 1.25$ & $48.62 \pm 19.15$ \\
\hline P-value & N.S & N.S & N.S & N.S & N.S \\
\hline
\end{tabular}

(Level of Significance $=P<0.05$ ) 
Table III : Mean and SD of number of follicles, oocytes and grade (a) embryos in the studied protocols.

\begin{tabular}{|l|c|c|c|}
\hline \multicolumn{1}{|c|}{ Protocol } & $\begin{array}{c}\text { Follicular number } \\
\text { Mean } \pm \text { SD }\end{array}$ & $\begin{array}{c}\text { Oocyte number } \\
\text { Mean } \pm \text { SD }\end{array}$ & $\begin{array}{c}\text { Embryo number } \\
\text { Mean } \pm \text { SD }\end{array}$ \\
\hline Short $(n=96)$ & $9.9 \pm 4.9$ & $7.8 \pm 5.2$ & $3.6 \pm 2.4$ \\
\hline Low cost $(n=139)$ & $6.5 \pm 5.2$ & $5.2 \pm 4.0$ & $2.9 \pm 1.8$ \\
\hline P-value & $0.06($ N.S $)$ & $0.001^{*}$ & $0.003^{*}$ \\
\hline
\end{tabular}

$(* \mathrm{P}<0.05)$

Table IV : Number of hMG ampoules / patient.

\begin{tabular}{|l|c|c|c|c|}
\hline \multirow{2}{*}{ Outcome } & \multicolumn{2}{|c|}{ Short protocol $(\mathrm{N}=96)$} & \multicolumn{2}{c|}{ Low cost protocol $(\mathrm{N}=139)$} \\
\cline { 2 - 5 } & Mean & $\pm \mathrm{SD}$ & Mean & $\pm \mathrm{SD}$ \\
\hline $\begin{array}{l}\mathrm{hMG} \\
\text { ampoules/pt }\end{array}$ & 31.53 & 4.81 & 9.12 & 2.61 \\
\hline $\mathrm{P}-$ value & & & & \\
\hline
\end{tabular}

* Very High Significant difference between short and low cost protocols.

Table V : Details of incompleted trials in both groups.

\begin{tabular}{|l|c|c|c|c|}
\hline \multirow{2}{*}{$\begin{array}{c}\text { Causes of } \\
\text { cancellation }\end{array}$} & Short protocol $(\mathrm{N}=96)$ & Low cost protocol $(\mathrm{N}=139)$ & $\begin{array}{c}\text { X2 (Yates } \\
\text { corrected) }\end{array}$ & P value \\
\cline { 2 - 5 } $\begin{array}{l}\text { Poor } \\
\text { response }\end{array}$ & No(\%) & No $(\%)$ & 0.00 & $0.96(\mathrm{NS})$ \\
\hline $\begin{array}{l}\text { Negative } \\
\text { TESE }\end{array}$ & $6(2.1)$ & $4(2.88)$ & 7.7 & $<0.01$ \\
\hline $\begin{array}{l}\text { Negative } \\
\text { fertilization }\end{array}$ & $11(11.46)$ & $28(20.1)$ & 0.24 & $0.62(\mathrm{NS})$ \\
\hline Total & $19(19.8)$ & $12(8.6)$ & & \\
\hline
\end{tabular}

Table VI : Incidence of Pregnancy Rate per Embryo Transfer.

\begin{tabular}{|l|c|c|c|c|}
\hline \multirow{2}{*}{ Outcome } & \multicolumn{2}{|c|}{ Short protocol $(\mathrm{N}=77)$} & \multicolumn{2}{c|}{ Low cost protocol $(\mathrm{N}=95)$} \\
\cline { 2 - 5 } & No. & $\%$ & No. & $\%$ \\
\hline Positive pregnancy & 20 & 25.9 & 21 & 22.1 \\
\hline Negative pregnancy & 57 & 74.1 & 64 & 67.4 \\
\hline P- value & $0.85(\mathrm{NS})$ & & \\
\hline
\end{tabular}


Table VII : Incidences of Multiple Gestations (Twins) Per ET in Both Groups .

\begin{tabular}{|c|c|c|}
\hline Short protocol $(\mathbf{n}=\mathbf{3})$ & Low cost protocol $(\mathbf{n}=\mathbf{5})$ & $\mathbf{P}$ - value \\
\hline $3.9 \%$ & $5.2 \%$ & 0.68 (NS) \\
\hline
\end{tabular}

\section{DISCUSSION}

Stimulation protocols for recruitment of multiple healthy fertilizable oocytes for in vitro fertilization (IVF) have been constantly evolving over the last 25 years. Since the retrieval of a single oocyte during the preovulatory phase of the natural cycle was abandoned in the early 1980 s in favor of using gonadotropins for stimulation of multiple oocytes. The protocols used have been in a state of dynamic change depending on the availability of stimulatory agents.

Controlled ovarian hyperstimulation $(\mathrm{COH})$ for IVF has evolved since its initiation in the late 1970 s to a highly specialized practice. This aspect of assisted reproduction, more than any other, has remained less a science and more a form of art, as evidenced by the numerous stimulation regimens published for responder of all types ${ }^{(11)}$.

The concept of $\mathrm{COH}$ emerged from the practice of in vitro fertitization (IVF). Although Louise Brown was born following in vitro fertilization-embryo transfer (IVF-ET) in a natural cycle, it soon became clear that the pregnancy rate was greatly improved if more than one embryo was replaced in the uterus (12). Thus, the aim of any regimen for controlled ovarian stimulation was to obtain as many follicles as possible from which good quality oocytes could be collected. However, the simultaneous risks of ovarian hyperstimulation syndrome (OHSS) and multiple pregnancies have led to the adoption of a compromise betwecn pregnancy rates and multiple follicular developments, and restriction in the number of embryos transferred (13)

Clomiphene citrate (CC) in conjunction with FSH or hMG has been used for ovarian stimulation for nearly 3 decades (14). Although comparisons between this regimen and $\mathrm{GnRH}$-a-FSH regimens have demonstrated improved oocyte production with the latter ${ }^{(15)}$, CC-FSH has continued to be used to improve simulation outcome in low responders (16) A majority of the regimens using $\mathrm{CC}$ and $\mathrm{FSH}$ had begun treatement with FHS later than initiation of FSH treatment in pure gonadotropin cycles, usually on cycle day 6 instead of day $3^{(17)}$.

The use of Clomiphene citrate in combination with gonadotropin was first recommended for patients undergoing IVF. However, the effectiveness of such a regimen has been hindered by the risk of a premature spontaneous luteinizing hormone (LH) Surge which occurs in about $20 \%$ of stimulated cycles and leads to IVF cancellation or impaired oocyte quality (18). Therefore, gonadotropin releasing hormone (GnRH) agonists, by preventing an untimely LH surge, have offered an effective alternative to this regimen and this approach has been used since the mid-1980s (19)

In the present study, the number of th grown follicles, retrieved oocytes and transferred embryos were lesser in number in patients treated by low cost protocol than those in short agonist protocol. This difference was statistically significant regarding the number of oocytes retrieved and the number of cmbryos available for transfer but statistically 
insignificant regarding the number of growing follicles. The same results have been found by

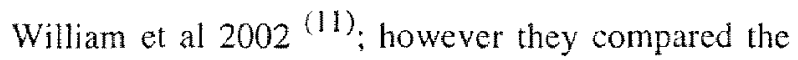
long agonist protocol with the low cost protocol. Also, Weghofer et al $(2004)^{(25)}$ and amato et al $(2004)^{(26)}$ reported that, the number of the mature oocytes retrieved was significantly less with the low cost protocol than in the short agonist protocol (t $1 \& 25)$

Regarding the total number of hMG ampoules used for follicular growth, women who used the short agonist protocol received much more hMG ampoules (31.5 \pm 4.81$)$ than women who used the low cost protocol (9.0 2.61$)$ giving rise to a highly statistically significant difference $(\mathrm{P}<0.001)$. Similar results have been reported by William et al $2002^{(20)}$.

There were no statistically significant differences in pregnancy rate between women who used the short protocol and those who used the low cost protocol. Similar results were reported by Weigert et al (2002); Engel et al (2002) and Hwang e al (2003) $(22,23,24)$.

Similar to the results of the present study, Weghofer et al (2004) and Amato et al (2004) found that although the number of the mature oocytes retrieved was significantly less with the low cost protocol, the pregnancy rate and implantation rates were similar between the two groups when they compared the long agonist protocol with the low cost protocol $(25,26)$.

In the present study, there were no reported cases of ovarian hyperstimulation syndrome in either group.

There were no statistically significance differences between both studied groups as regard to the occurrence of multiple gestations. Noting that; all cases of multiple pregnancies recorded were twins.

The failure of completing the trial was higher in the low cost protocol than in the short protocol.
However; this difference was statistically insignificant. Negative TESE was the main cause for aborting the trial in the majority of cases. This may lead to consider the advantage of using the low cost protocol instead of the ordinary short protocol when the possibility of negative TESE is highly expected especially in those male partners of non obstructive azoospermia to minimize the trial cost.

\section{CONCLUSION}

The low cost protocol was found markedly less expensive than the short protocol, with unremarkable significance comparing completed trial outcome. So, it could be used as an alternative to the short protocol especially in couples undergoing ICSI and/or TESE aiming at cost reduction.

\section{REFERENCES}

1. Ingerslev HJ, Hojgaard A, Hindkjaer J and Kesmodel U (2001): A randomized study comparing IVF in the unstimulated cycle with IVF following Clomiphene citrate. Hum Reprod 16: 696-702.

2. Templeton A and Morris JK 1998 reducing the risk of multiple births by transfer of two embryos after in vitro fertilization. N Engl J Med 339: 573-577.

3. Fauser BC, Devroey P, Yen SS, Gosden R, Crowley WF, Baird DT, Bouchard P 1999 Minimal ovarian stimulation for IVF: appraisal of potential benefits and drawbacks. Hum Reprod.

4. Edwards RG, Lobo R, Bouchard P 1996 Time to revolutionize ovarian stimulation. Hum Reprod 11 917-919.

5. Femke P. Hohmann, Nicholas S. Macklon and Bart C. J. M. Fauser (2003): A randomized Comparison of Two Ovarian Stimulation Prolocols with Gonadotropin-Releasing Hormone (GnRH) 
Antagonist Cotreatment for in Vitro Fertilization Commencing Recombinant Follicle-Stimulating Hormone on Cycle Day 2 or 5 with the Standard Long GnRH Agonist Protocol. J of clinic endo \& metabol 88:166.

6. Corfman RS, Milad MP, Bellavance TL, Ory SJ. (1993): A novel ovarian stimulation protocol for use with the assisted reproductive technologies. Fertil Steril, $60,864-870$.

7. Dor J, Seidman DS, Ben-Shlomo I, Levran D, Ben-Rafael Z, Mashiach S 1996 Cumulative pregnancy rate following in vitro fertilization: the significance of age and infertility etiology. Hum Reprod 11:425-428.

8. Toner JP, Philput CB, Jones GS, Muasher SJ 1991 Basal follicle stimulating hormone level is a better predictor of in vitro fertilization performance than age. Fertil Steril 55: 784-791.

9. Scott Jr RT, Hofmann GE 1995 Prognostic assessment of ovarian reserve. Fertil Steril 63: 1-11.

10. Scott RT, Toner JP, Muasher SJ, Oehninger S, Robinson S, Rosewaks Z. (1989) Follicle stimulating hormone level on cycle day 3 are predictive of in vitro outcome. Fertil steril; 51: 651-654.

11. Williams SC, Gibbons WE, Muasher SJ and Oehninger S (2002) Minimal ovarian hyperstimulation for in vitro fertilization using sequential clomiphene citrate and gonadotropin with or without he addition of a gonadotropin-releasing hormone antagonist. Fertil Steril 78: 1068.

12. Fishel SB (1985): Implantation, abortion and birth after in vitro fertilization using the natural menstrual cycle in follicular stimulation with clomiphene citrate and human menopausal gonadotrophin. Journal of In Vitro Fertility and Embryonic Transfer, $1985,2: 123-131$.
13. Dawson KJ. Reducing triplet pregnancies following in vitro fertilization (Letter). Lancet, 1991, 337 : $1543-1544$.

14. Diamond MP, Hill GA, Webster BW, Herbert CM (1986): comparison of human menopausal gonadotropin, clomiphene citrate and combined human menopausal gonatotrpin-clomiphene citrate stimulation protocol for in vitro fertilization. Fertil Steril $46: 1108$.

15. Tummen IS, Daneil SAJ, Kaplan BR Nisker JA (1992): Randomized, prospective comparison of luteal Leuprolide acetate and gonadotropins versus clomiphene citrate and gonadotropins in 408 first cycles of in vitro fertilization. Fertil Steril 12:8.

16. Benadiva CA, Davis O, Kligman I, Liu HC (1995): Clomiphene citrate and hMG: an alternative stimulation protocol for selected failed in vitro fertilization patients. J assist Reprod Genet; 12:8.

17. Corfman RS, Milad MP, Bellavance TL (1993): an altemative stimulation protocol for use with the assisted reproductive technologies. Fertil Steril; 60: 864.

18. Tarlatzis BC. Oocyte collection and quality. Assisted Reproduction Reviews, 1992, 2: 16-22.

19. Tarlatzis BC. Oocyte collection and quality. Assisted eproduction Reviews, 1992, 2: 16-22.

20. Weghofer A, Margeiter M, Bassim S, Selvada U (2004): Minimal stimulation usinr recombinant follicle stimulating hormone and gonadotrophins releasing hormone antagonist in women of advance dage. Fertil Steril; 81: 102-106.

21. D'Amato G. Carppo E; Pasquadisceglie A et at (2004): A novel protocol for ovarian induction with delayed gondotrophins releasing hormone antagonist administration combined with high dose recombinant follicle stimulating hormone and clomiphene citrate for poor responders and women 
over 35. Fertil Steril; 81: 1572-7.

22. Weigher $M$ Krischker u Pohl M et al (2002): Comparison of stimulation with Clomiphene citrate in combination with recombinant follicle stimulation with a gonadotrophin releasing hormone agonist protocol: a prospective randomized siudy. Fertil. Steril 87: 34-9.

23. Engel JB Ludwig M Felbrebaum $R$ et al (2002): Use of cetrrorelix in combination with clomibphene citrate and gonadotropins: a suitable approach 10 friendly IVF. Hum Reprod 17: 2022-2026.

24. Hwang JL Huang LW Hsieh BC et al (2003): Ovarian stimulation by clomiphene citrate and $\mathrm{hMG}$ in combination with centrorelix acetate for ICSI cycles. Hum Reprod 18: 45-9.

25. Weghofer A, Margreiter M, Bassim S, Selvada U (2004): Minimal stimulation usinr recombinant follicle stimulating hormone and gonadotrophins releasing hormone antagonist in women of advance age. Fertil Steril, 81: 102-106.

26. D' Amato G, Carppo E; Pasquadisceglie $A$ et al (2004): A novel protocol for ovarian induction with delayed gonadotrophins releasing hormone antagonist administration combined with high dose recombinant follicle stimulating hormone and clopiphene citrate for poor responders and women over 35. Fertil Steril; $81: 1572-7$. 